\title{
Dissemination of International Humanitarian Law and of the Principles and Ideals of the Red Cross
}

\author{
Summary of Work from 1 December 1981 to 15 August 1983
}

This report was submitted jointly by the ICRC and the League to the Council of Delegates in October 1983, pursuant to paragraph 4 of the tenth resolution of the Twenty-fourth International Conference of the Red Cross (Manila, 1981) which: "requests the ICRC and the League to report jointly to the next meeting of the Council of Delegates... on international, regional and national dissemination action and on the follow-up of the present resolution". This report relates to the period from 1 December 1981 to 15 August 1983.

It should be noted that the dissemination of knowledge of international humanitarian law and of the principles and ideals of the Red Cross is a sphere of activity in which co-operation between the ICRC, the League, the National Red Cross and Red Crescent Societies and the Henry Dunant Institute is constantly becoming closer and more extensive. Although this report deals only with dissemination activities undertaken by the institutions in Geneva, it goes without saying that numerous National Societies have also been extremely active in implementing their own action programmes.

\section{GENERAL OVERVIEW}

\section{The Programme of Action}

In 1981, the ICRC and the League adopted the "Second Programme of Action of the Red Cross for the Dissemination of International Humanitarian Law and of the Principles and Ideals of the Red Cross" for the period 1982-1985. This programme contains guide-lines for the activities of the ICRC, which has made dissemination one of its prime objectives for the years ahead. In effect, the need for dissemination is 
highlighted every day by the tragic realities of contemporary armed conflicts. The experiences of ICRC delegates in combat zones invariably show that unawareness of the essential rules of international humanitarian law among the armed forces and in government circles is a frequent cause of serious infractions in respect of protected persons and usually constitutes a major obstacle to the proper discharge of the humanitarian tasks of the Red Cross.

The League, one of whose functions is "to assist the ICRC in the promotion and development of international humanitarian law and collaborate with it in the dissemination of this law and of the Fundamental Principles of the Red Cross among the National Societies", has included the dissemination of the humanitarian rules and the principles of the Red Cross as part of its activities, especially during its seminars or training courses for National Societies. It has also collaborated actively in several projects for which the main responsibility lay with the ICRC.

\section{Eight target groups, four levels of knowledge}

Although, ideally, every human being should be a ta1get for dissemination activity, the magnitude of the task has compelled the Red Cross to establish a scale of priorities. Eight target groups are therefore listed in the programme of action:

- firstly, the armed forces which, in time of war, are responsible for the practical application of the rules of international humanitarian law;

- the staff and volunteers of the National Red Cross and Red Crescent Societies who constitute a target group while, at the same time, acting as dissemination media;

- government circles which have the dual responsibility of making known and ensuring the application of international humanitarian law;

- the universities in which tomorrow's elite receive their training;

- the schools, since the concepts of humanitarianism, peace and international understanding must be instilled into young people's minds;

- medical circles whose task is to protect life and health, and which thereby contribute to one of the missions of the Red Cross;

- journalists who exert an undeniable influence on contemporary society;

- finally, the general public, whose interest is most readily aroused by the dramatic and tragic events that take place in our world, the more so when they are themselves directly affected. 
Moreover, in order to better adapt the content and form of the message to be disseminated to the various target groups, it has been deemed appropriate-at the risk of appearing rather arbitrary-to transmit such knowledge at four different levels:

Level I: elementary knowledge

Level II: general knowledge

Level III: specialized knowledge

Level IV: expert knowledge

In future, these four levels should be borne in mind when establishing national action programmes and also when devising teaching aids and during the training of specialized personnel.

\section{Dissemination as an integral part of the development programme}

In accordance with the guide-lines approved by the Twenty-third and Twenty-fourth International Red Cross Conferences, each National Society should appoint one of its officials to disseminate the message of the Red Cross. An interministerial committee should also be set up to organize the dissemination of international humanitarian law among the various target groups, through the administrative channels of their respective States.

Facts must be faced, however; although a remarkable effort has been made by several National Societies, it must be admitted that many others do not possess the resources needed to finance the assignment of a fulltime official or to devise and produce the requisite teaching aids.

Consequently, in countries where the Red Cross or Red Crescent possess neither the resources nor the personnel needed to undertake the dissemination of the message of the Red Cross on their own, the ICRC, in liaison with the League, should provide them with assistance by, on the one hand, helping them to establish a programme of action adapted to local circumstances and, on the other hand, by helping with its implementation until such time as the Society is able to take over on its own. The important thing is not only to help get an operation going but also, above all, to ensure its continuity.

For the ICRC the years 1982 and 1983 therefore mark the beginning of a new stage in its dissemination endeavours. Faced with the abovementioned difficulties, it has, in effect, taken the first steps towards the gradual establishment of a network of specialized delegates to help National Red Cross and Red Crescent Societies to organize and implement their national action programmes. By the end of June 1983, four regional ICRC delegations in East Africa (Nairobi), West Africa 
(Lomé), South-East Asia (Manila) and Central America (San José) had been supplemented in this way by the assignment of a full-time "dissemination" delegate. These delegates also have the task of co-ordinating a possible specific contribution by the ICRC to the development of the National Societies, in close collaboration with the League as the institution primarily responsible for such development.

One of the first duties of ICRC "dissemination" delegates is to help with the establishment and/or development of information and public relations services within the Societies of their region since, in the case of many Societies, such services are responsible for the dissemination of the essential rules of international humanitarian law and the principles and ideals of the Red Cross. The ICRC helps, in particular, with training programmes organized by the League for officials of these information and public relations services from the point of view not only of the knowledge to be acquired, but also of the ways and means of getting the Red Cross message through.

The following three highly successful pilot projects, in which the League and the ICRC took an active part, should be noted:

- the training course at Turrialba (Costa Rica, September 1982) which was attended by 10 Latin American National Red Cross Societies;

- the "Workshop" organized at Cartagena (Colombia, March 1983) for the senior staff of Societies in formation in the Caribbean;

- the Sub-regional Training Workshop for primary health care, instruction in the field, organized in May 1983 by the Centre d'Etudes des Sciences et Techniques de l'Information (CESTI) of the University of Dakar (see below under "Dissemination among National Societies").

\section{Dissemination in "hot situations"}

Apart from establishing the nucleus of a network of "dissemination" delegates at the regional level, in recent months the ICRC has endeavoured to complement some of its delegations by despatching a specialized delegate responsible for setting up emergency dissemination programmes in collaboration with the National Societies concerned. These programmes are designed to promote knowledge and understanding of the essential rules of international humanitarian law among combatants, leaders and the civilian population, and also to explain the guiding principles of Red Cross activities. Such programmes were put into effect in 1982 and/or 1983 in El Salvador, Lebanon, Poland and Pakistan (in the Afghan frontier zone). 


\section{Teaching aids}

The availability of the basic teaching aids (printed + audio-visual material) required by national and international institutions in order to carry out their dissemination activities unfortunately still falls far short of the needs, in particular of the target groups at levels I (elementary knowledge) and II (general knowledge).

\section{Printed material}

The following publications, produced at Geneva within the context of the dissemination programme, have been issued or are due to be printed by the end of 1983 :

A Practical Guide for National Societies on Methods of Dissemination of International Humanitarian Law and the Principles and Ideals of the Red Cross. This much-awaited document is the result of team work by representatives of the ICRC and the League under the direction of Miss Danuta Zys (Henry Dunant Institute). It will be available in English, French and Spanish in October 1983.

Protection of the Victims of Armed Conflict Falkland/Malvinas Islands (1982): International Humanitarian Law and Humanitarian Action. This booklet of about 60 pages researched and written by Mrs. Sylvie Junod, a jurist at the ICRC, is currently available in mimeograph form in French, English and Spanish. It will be distributed in printed form in late 1983/early 1984.

Origin and Development of International Humanitarian Law. Written by Miss Françoise Bory, press attaché at the ICRC, this small booklet gives a straightforward account of the evolution and content of international humanitarian law. It is available in French, English, Spanish, Arabic, German and Portuguese (about 40 pages in format A6).

Manual on the Rights and Duties of Medical Personnel in Armed Conflicts. This 80-page booklet, researched and written by Dr. Alma BaccinoAstrada at the request of the League and the ICRC, summarizes the provisions of the Geneva Conventions and their Protocols concerning the protection of the medical professions in time of war and the role of military and civilian medical personnel. This manual has been published in French, English, Spanish and Arabic. It replaces the booklet entitled "Rights and Duties of Nurses".

Essential Rules of the Geneva Conventions and their Additional Protocols. This guide, published by the ICRC, will be available in French and English at the end of 1983. It will replace the booklet entitled "Handbook of the Geneva Conventions-Essential Rules". 
Les Histoires de Noko Lisapo. This is a 16-page illustrated magazine which relates seven stories told by Noko Lisapo to his African brothers and reviews various episodes of the history and activities of the ICRC. The magazine, available only in French, was written by Mr. Michel Bory and illustrated by Mr. Nicolas Luginbühl, both of whom are ICRC delegates.

The Identification of Medical Aircraft in Periods of Armed Conflict and Identification of Hospital Ships and Ships Protected by the Geneva Conventions of 12 August 1949. These two studies written by Mr. Philippe Eberlin, an expert at the ICRC, are available in French, English and Spanish in the form of extracts, printed under separate cover, from the International Review of the Red Cross.

Teacher's Handbook. This guide, prepared by the Cameroon Red Cross with the assistance of the League and the ICRC, was adapted in 1982 and 1983 for the National Societies of Mauritania, Senegal, Poland, Costa Rica, Peru and Colombia.

The Philippine National Red Cross and the ICRC delegation in Manila have jointly prepared, in the form of a strip cartoon in English for young persons of that country, a series of six stories explaining the activities and guiding principles of the national and international Red Cross. A similar experiment has also been carried out by the ICRC delegation at Peshawar for the benefit of Afghans temporarily in Pakistan or seeking refuge there.

Reference should also be made to the issue, in September 1983, of a new series of seven posters illustrating the fundamental rules that every soldier should observe with regard to non- or ex-combatants.

\section{Audio-visual material}

Production in the audio-visual field remained fairly limited. The main item was a co-production by the Hungarian and Bulgarian National Red Cross Societies, the League and the ICRC entitled What's in a symbol? This 27-minute documentary, produced by Dr. György Karpati of Budapest, is mainly intended for young audiences of 13 to 18 years of age. It explains the fundamental principles, history, structure and activities of the Red Cross. The film is available in $35 \mathrm{~mm}$ and $16 \mathrm{~mm}$ English, French, Spanish, Arabic, Bulgarian, Hungarian and German versions.

In 1982, the ICRC produced a series of four $16 \mathrm{~mm}$ half-hour films, in French only, based on the stories of Noko Lisapo. This series, shot on location in Senegal, features local actors under the direction of Mr. Michel Bory, an ICRC delegate. 
The Audio-Visual Centre for the International Red Cross also produced several video films. Special reference must be made to the following:

International humanitarian law : a limit to barbarity. The principal objective of this 25-minute cassette produced by Mr. Jean-Jacques Surbeck, head of the Dissemination Service of the ICRC, is to illustrate the importance of dissemination as a means to limit excesses in warfare. It is available in French, English and Spanish versions.

The Central Tracing Agency: a 26-minute cassette describing the various activities of this important department of the ICRC, produced by Mr. Jean-Daniel Bloesch, an ICRC delegate and film director, (in French, English and Spanish versions).

The ICRC also produced two sets of slides with sound-recorded commentary. The first, running for 10 minutes, is entitled The Red Cross and Peace (in English and French versions) and the second, running for 12 minutes, is on the subject of The Fourth Geneva Convention (Israel) (in French, English and Arabic versions). Both sets of slides, produced by Mr. Jean-Luc Rey, are also available in the form of video cassettes.

\section{DISSEMINATION OPERATIONS BY TARGET GROUP}

\section{Dissemination among the armed forces}

The ICRC organized seminars, took part in various courses and meetings on the law of war, invited officers to attend a training session at its headquarters and carried out missions to promote the dissemination and teaching of international humanitarian law among the armed forces. These tasks were undertaken mainly by the delegate to the armed forces.

The "dissemination" delegates stationed in various countries also gave special attention to this priority target group, particularly the armed forces and security services in El Salvador and various groups of Afghans temporarily in the Peshawar region.

\section{Courses and meetings}

The twelfth international course on the law of war, organized by the International Institute of Humanitarian Law, was held at San Remo in October 1982. As in previous years, the course was directed by the ICRC delegate to the armed forces and was intended for senior officers holding positions of command in their national armed forces, experienced general 
staff officers, and officers responsible for giving instruction in the law of war. The purpose of these courses, which last two weeks, is to familiarize participants with the provisions of international treaties (the Hague Conventions, the Geneva Conventions, the Additional Protocols), taking military realities into account.

The twelfth course, given in English, was attended by 55 senior officers from the following countries: Australia, Canada, Denmark, Egypt, Finland, Federal Republic of Germany, Greece, Haiti, Iran, Iraq, Italy, Netherlands, Norway, Philippines, Senegal, Spain, Sweden, Switzerland, Thailand, United Kingdom, United States, Zambia and Zimbabwe. The steady rise in the level of participants was noteworthy, since the course was attended by nine generals and most of the participants were senior officers. As usual, a number of jurists, six in 1982, also spoke on various subjects, thus widening the scope of the instruction given and making a valuable contribution to the course.

The first Egyptian seminar on international humanitarian law was held in Cairo from 20 to 24 November 1982. It was organized by the Egyptian Society of International Law, with the co-operation of the ICRC, primarily for senior officers (combatants or military lawyers). It was attended by about thirty Egyptian and two Sudanese officers, together with a number of university professors and senior government officials. Eight lectures, each followed by a discussion, were delivered on the following subjects: an introduction to international humanitarian law; the law of war and the armed forces; the Additional Protocols; ICRC activities and the application of international humanitarian law in the Middle Eastern context; international humanitarian law and Islam; the protection of civilians during armed conflicts; rules of conduct in combat; international humanitarian law and wars of liberation.

The ICRC delegate to the armed forces, accompanied by his assistant, directed a training course in the law of war in Beirut, Lebanon, from 25 July to 5 August 1983. This course, held under the auspices of the high command of the Lebanese army, was attended by 647 officers. The instruction, which was mainly geared to the needs of the lower ranks (privates, non-commissioned and junior officers), was concerned primarily with command and behaviour under combat conditions.

In 1982, for the first time, training programmes for officers were organized in Geneva by the ICRC. These programmes, supervised by the delegate to the armed forces, consisted of a course in the law of war given at the Henry Dunant Institute along the lines of the San Remo courses. However, in contrast to the latter which are intended for a multinational audience, the purpose of these courses is to train officers 
from a specific country to organize teaching programmes among their own armed forces, taking into account their particular local needs. In 1982, one Zairian and four Philippine officers benefited from these courses.

On 18 February 1982, the delegate to the armed forces attended a meeting with German military commanders at Arolsen. The subject discussed at the meeting was the protection of civilians and the environment during military operations. At the end of September 1982, he took part in the "Inter-American Seminar on State Security, Human Rights and International Humanitarian Law" (see below under "Dissemination in government circles"). The delegate to the armed forces also represented the ICRC at the "Ninth Congress of the International Society of Penal Military Law and Law of War" held at Lausanne, Switzerland, from 2 to 6 September 1982. He maintained contact with the "International Committee of Military Medicine and Pharmacy" and the "International Society of Penal Military Law and Law of War" in connection with the organization and co-ordination of courses and seminars for officers.

\section{Dissemination among National Societies}

ICRC representatives took part in the organization and running of several seminars and carried out a number of missions to National Societies with a view to assisting them in their dissemination endeavours. For example, a delegate visited Nicaragua from late June until early August 1982 to give lectures on international humanitarian law and the principles of the Red Cross at the headquarters of the National Society and in a score of its branches.

\section{Courses and seminars}

As already mentioned, a training course on international humanitarian law and the principles of the Red Cross was organized by the ICRC, in co-operation with the League and the Costa Rica Red Cross, at Turrialba (Costa Rica) from 12 to 18 September 1982. It was attended by 22 persons in charge of dissemination, information or training, together with some jurists, from 10 National Societies (Bolivia, Costa Rica, Cuba, Dominican Republic, El Salvador, Guatemala, Honduras, Mexico, Nicaragua and Panama). The aim of the course was twofold: to broaden the participants' knowledge in the field of international humanitarian law and to discuss dissemination methods best suited to their countries. At the end of the course, dissemination programmes were drafted for each National Society to submit to its respective authorities. 
A "workshop" on dissemination and development was organized by the League and the ICRC, in Cartagena (Colombia) in March 1983, for the senior officials of Societies in formation in the Caribbean States of Antigua, Belize, Dominica, Saint Lucia, Saint Vincent and the Grenadines, and Suriname. All are aware of the importance of the dissemination of international humanitarian law and have declared themselves ready to incorporate this activity in their respective development programmes.

The ICRC also sent representatives to the following seminars or meetings organized by National Societies:

- the dissemination day organized by the Belgian Red Cross in March of 1982 and 1983 ;

- the first national training seminar on the dissemination of international humanitarian law, held by the French Red Cross at BoisLarris, near Paris, on 24 and 25 May 1982, which was attended by several officials appointed by the National Society to take charge of dissemination in the various French departments;

- The meeting of Nordic Red Cross Societies organized by the Norwegian Red Cross in Oslo from 2 to 4 August 1982; the purpose of this meeting, attended by the ICRC, the League and the Henry Dunant Institute, was to review the dissemination and information activities of those National Societies and to examine ways and means of co-operation with the institutions in Geneva in this respect;

- two seminars on dissemination organized at Santiago in October 1982 by the Chilean Red Cross and the Chilean Ministry for Foreign Affairs; one was for high-ranking officers in the armed forces and senior officials of the Ministry for Foreign Affairs, and the other for journalists and for members of the National Society;

- the national meeting organized at Guaranda in November 1982 by the Ecuadoran Red Cross to discuss the dissemination of knowledge of the principles of the Red Cross;

- the seminar organized in February 1983 by the Golden Gate Chapter of the American Red Cross (San Francisco) on international humanitarian law and human rights.

Dissemination in government circles

Inter-American seminar in Costa Rica

An Inter-American Seminar on State Security, Human Rights and International Humanitarian Law was organized jointly by the ICRC and 
the Inter-American Institute of Human Rights. The governments of the Americas were invited to send participants (senior officers in the armed forces, high officials in the Ministries of Foreign Affairs, Defence, the Interior, Justice, etc.). The seminar was held at San José, Costa Rica, from 27 September to 1 October 1982.

\section{Dissemination in universities}

\section{Washington Seminar on International Humanitarian Law}

To commemorate the centenary of the accession of the United States to the 1864 Geneva Convention, the American University's Washington College of Law and the American Red Cross, with ICRC support, organized a seminar on international humanitarian law in the federal capital from 11 to 12 March 1982 . The seminar was attended by about a hundred university professors, government and military lawyers and advanced law students. The programme comprised a number of lecturers and discussions on various aspects of international humanitarian law and its relationship with human rights.

In view of the successful outcome of this first seminar, the American University's Washington College of Law repeated the experiment on 12 and 13 April 1983. The second seminar was attended by about forty specialists, including two representatives of the ICRC.

\section{Canberra Seminar}

The first regional seminar on international humanitarian law for university professors and government representatives from the Asian/ Pacific region was held at Canberra (Australia) from 6 to 12 February 1983. It was organized by the Australian Red Cross, the National University of Australia and the Henry Dunant Institute, with support from the ICRC, which sent representatives. The regional representative of the League also attended.

\section{Honolulu Seminar}

After the Canberra seminar, the representatives of the ICRC, the League and the Henry Dunant Institute travelled to Hawai to attend a four-day seminar from 16 to 19 February 1983, organized by the American Society of International Law in collaboration with the American Red Cross, the ICRC and other bodies.

\section{University Seminar in Poland}

A Seminar on international humanitarian law for assistant lecturers in faculties of law at Polish universities was held at Warsaw, under the 
auspices of the Polish Red Cross, from 21 to 23 April 1983. About fifteen assistant lecturers and postgraduate students attended the lectures given on aspects of international humanitarian law and the activities, structure and organization of the ICRC. Special interest was shown in the protection operation undertaken by the ICRC in Poland.

The legal adviser sent from Geneva to speak at the seminar also addressed a gathering of students at the University of Lodz, a meeting of professors at the University Military School in the same city, a group of senior officials from the Ministry of Justice and the staff at the headquarters of the Polish Red Cross.

International Review mentioned these seminars in previous issues.

\section{Strasbourg course}

For several years, the ICRC and the Henry Dunant Institute have been participating regularly in the July courses held in Strasbourg by the International Institute of Human Rights. They made an active contribution to the 1982 and 1983 sessions by providing teachers for the courses, which are designed for persons desiring further training in the field of human rights and international humanitarian law.

\section{Lectures}

\section{... in Paris}

On 26 February 1982, the ICRC Director for General Affairs was invited to speak at the "Ecole Nationale d'Administration" in Paris, where he delivered a lecture on the ICRC, its history and international humanitarian law.

\section{... in Nice}

On 28 and 29 January 1982, two ICRC jurists took part in a seminar on current problems of international humanitarian law organized by the Institute for Peace and Development of the Faculty of Law at the University of Nice.

\section{$\ldots$ and in Belgium}

On two occasions ( 2 to 6 March 1982 and 27 February to 6 March 1983), an ICRC jurist delivered lectures on the ICRC and various problems of international humanitarian law in the Universities of Louvain (Faculties of Law and Political and Social Sciences), Liège (Faculty of Law) and Brussels (Faculty of Law). 
Training courses for university professors

In 1982 and 1983, the ICRC organized training courses at its headquarters for university professors wishing to specialize further in international humanitarian law. The participants came mainly from Asia (People's Republic of China, India and Syria) and Africa (Algeria, Ethiopia, Morocco, Sierra Leone, Sudan and Tanzania).

\section{Dissemination among young people}

Meetings

As in the past, the ICRC took part in the European meeting of national Youth Red Cross directors organized by the League. The sixth meeting was held at Tulin, near Vienna, from 9 to 15 May 1982. The participating National Societies exchanged views on their experiences in the field of dissemination among young people.

In order to promote better knowledge and understanding of the Red Cross, international humanitarian law and human rights, the Norwegian Red Cross organized, for the first time, a seminar for secondary school teachers of the humanities and social sciences. The seminar, in which the ICRC took part, was held at Oslo from 28 to 31 October 1982. It was attended by some twenty-five teachers.

\section{Dissemination in medical circles}

The French Red Cross invited the ICRC to take part in a seminar which it organized at the Beaujon Hospital in Paris, from 19 to 21 November 1982, for the purpose of preparing its voluntary workers for international humanitarian missions. The seminar, the first of its kind to be held in France, was primarily intended for medical and logistics personnel. Two ICRC representatives spoke on the International Red Cross, specific Red Cross missions, and the application of the Geneva Conventions during such missions.

In June 1983, the same National Society decided to establish a training programme for all its medical personnel as part of its dissemination endeavours. An ICRC representative took part in the first phase of this programme organized for the personnel of the Henry Dunant Hospital, which is one of the three hospitals run by the French Red Cross in the Paris region.

Finally, reference must be made in this connection to the joint ICRCLeague publication Manual on the Rights and Duties of Medical Personnel in Armed Conflicts, written by Dr. Alma Baccino-Astrada, which has already been mentioned under "General Overview-Teaching aids". 


\section{PARTICIPATION OF THE HENRY DUNANT INSTITUTE}

In 1982 and 1983, the Henry Dunant Institute continued its activities for the dissemination of knowledge of international humanitarian law and the principles and ideals of the Red Cross. It endeavoured, in particular, to act on the resolution adopted by the Council of Delegates (Manila, November 1981) which encouraged it: “... to reinforce its contribution to the efforts of the ICRC in disseminating international humanitarian law; to continue to support the action of the ICRC and of the League in the dissemination of the principles and ideals of the Red Cross...". Its activities were also carried out in line with the 19821985 programme of action for dissemination.

\section{Publications}

The Institute continued its preparation of working documents and reference material on international humanitarian law for research workers, National Societies, etc., as exemplified by the following:

A "Teaching Manual on international humanitarian law (prepared in collaboration with UNESCO and the ICRC) and a "Glossary of terminology on the law of armed conflits", in English, French, Spanish and Russian, prepared under the direction of Professor I. Paenson (in collaboration with UNESCO, the "Institut Universitaire des Hautes Etudes Internationales" in Geneva, and the ICRC).

The "Practical Guide for National Societies on Methods of Dissemination of International Humanitarian Law and Principles and Ideals of the Red Cross", a draft of which was presented at Manila to a group of dissemination experts, was submitted to about forty National Societies. Their views were taken into account in the preparation of the final version. The purpose of this guide is to suggest to the National Red Cross and Red Crescent Societies specific methods to help them in their task of dissemination. It is intended for all National Societies, particularly those preparing a programme for the dissemination of knowledge of international humanitarian law and the principles and ideals of the Red Cross (see above under "General Overview-Teaching aids").

The Institute has also undertaken a study for the purpose of establishing a "Directory of universities and academic institutions for the promotion of the teaching of international humanitarian law". To this end, in 1983, it began a survey by sending questionnaires to National Societies and, through them, to universities and academic institutions in their respective countries. 


\section{Training courses}

The object of the Institute is to promote studies of a humanitarian nature. To this end, in 1982, it received twelve trainees, including several from National Societies, who undertook studies on the ICRC's right of humanitarian initiative, refugees status, and the Red Cross and peace. Students from the University of Santa Clara (California) and the International Institute of Human Rights (Strasbourg) also followed training courses at the Institute.

\section{Seminars}

In May 1982, the Institute organized its Seventh Annual Introductory Course on the International Activities of the Red Cross (in French), which was attended by 23 representatives from National Societies, including 11 African Societies.

The Eighth Course, given in English from 30 May to 10 June 1983, was attended by 33 representatives from National Societies.

In 1982 and 1983, the Institute organized its Second and Third Seminars on the Red Cross and international humanitarian law for members of permanent missions to the United Nations Office at Geneva, which were attended by 18 diplomats in January 1982 and 23 in January 1983. The aim of this type of seminar is to acquaint diplomats with the role and functions of the Red Cross and to familiarize them with the principles of international humanitarian law and certain basic aspects of its application.

The Institute also took an active part in the following seminars:

The Third African Seminar on international humanitarian law (in collaboration with the Cameroonian Institute of International Relations). This seminar, held at Yaoundé (United Republic of Cameroon) from 24 November to 2 December 1981, was attended by 55 participants from 29 African countries, together with 22 students from the Cameroonian Institute.

The Third Inter-American Seminar on international humanitarian law and the peaceful solution of disputes, held at Tampa, Florida, from 8 to 12 November 1982, was organized jointly by the Henry Dunant Institute and the Inter-American Bar Association. The seminar comprised two programmes: international humanitarian law and the peaceful solution of international disputes. It was attended by about ninety participants, mainly jurists.

The First Seminar on international humanitarian law for representatives of governments and academic institutions in the Asian/Pacific region, held 
at Canberra from 6 to 12 February 1983, was organized by the National University of Australia and the Henry Dunant Institute in association with the Australian Red Cross. The general subject was: "Protection of the human being in time of armed conflict". (See above under "Dissemination in universities".)

In all these courses and seminars, the Institute was assisted by experts from the ICRC and the League.

The Henry Dunant Institute also took part in a number of meetings organized by the ICRC, National Societies and specialized institutions. It was represented at a conference on international humanitarian law (11-12 March 1982) organized by the American Red Cross and the American University's Washington College of Law.

It also participated in a seminar on methods of disseminating knowledge of international humanitarian law and the principles of the Red Cross in the Nordic countries (Oslo, 2-4 August 1982) and in the Round Table organized by the San Remo Institute (8-11 September 1982).

Finally, the Institute participated in 1982 and 1983, as it does every July, in the teaching of international humanitarian law as part of the Summer Courses on Human Rights held by the International Institute of Human Rights at Strasbourg. 